\title{
Late Developmental Stage-Specific Role of Tryptophan Hydroxylase 1 in Brain Serotonin Levels
}

\author{
Kazuhiro Nakamura, ${ }^{1}$ Yuko Sugawara, ${ }^{2}$ Keiko Sawabe, ${ }^{2}$ Akiko Ohashi, ${ }^{2}$ Hiromichi Tsurui, ${ }^{1}$ Yan Xiu, ${ }^{1}$ Mareki Ohtsuji, ${ }^{1}$ \\ Qing Shun Lin, ${ }^{1}$ Hiroyuki Nishimura, ${ }^{3}$ Hiroyuki Hasegawa, ${ }^{2}$ and Sachiko Hirose ${ }^{1}$ \\ ${ }^{1}$ Department of Pathology, Juntendo University School of Medicine, Tokyo 113-8421, Japan, ${ }^{2}$ Department of Bioscience, Teikyo University of Science and \\ Technology, Uenohara, Yamanashi 409-0193, Japan, and ${ }^{3}$ Department of Biomedical Engineering, Toin Human Science and Technology Center, Toin \\ University of Yokohama, Yokohama 225-8502, Japan
}

Serotonin [5-hydroxytryptamine (5-HT)] is a major therapeutic target of psychiatric disorders. Tryptophan hydroxylase (TPH) catalyzes the rate-limiting reaction in the biosynthesis of 5-HT. Two isoforms (TPH1 and TPH2) having tryptophan hydroxylating activity were identified. Association studies have revealed possible TPH1 involvement in psychiatric conditions and behavioral traits. However, TPH1 mRNA was reported to be mainly expressed in the pineal gland and the periphery and to be barely detected in the brain. Therefore, contribution of TPH1 to brain 5-HT levels is not known, and the mechanisms how TPH1 possibly contributes to the pathogenesis of psychiatric disorders are not understood. Here, we show an unexpected role of TPH1 in the developing brain. We found that TPH1 is expressed preferentially during the late developmental stage in the mouse brain. TPH1 showed higher affinity to tryptophan and stronger enzyme activity than TPH2 in a condition reflecting that of the developing brainstem. Low 5-HT contents in the raphe nucleus were seen during development in New Zealand white (NZW) and SWR mice having common functional polymorphisms in the TPH1 gene. However, the 5-HT contents in these mice were not reduced in adulthood. In adult NZW and SWR mice, depression-related behavior was observed. Considering an involvement of developmental brain disturbance in psychiatric disorders, TPH1 may act specifically on development of 5-HT neurons, and thereby influence behavior later in life.

Key words: behavior; depression; RAPHE; serotonin; tryptophan hydroxylase; development

\section{Introduction}

Serotonin [5-hydroxytryptamine (5-HT)] has been implicated in a variety of physiological and pathological functions in CNSs (Lucki, 1998; Lesch, 2004). Numerous studies have suggested associations between various neuropsychiatric disorders and genes that modulate central serotonergic neurotransmission, such as the 5-HT transporter (Lesch et al., 1996), 5-HT receptors (Lucki, 1998), and monoamine oxidases (Shih et al., 1999). Therefore, the brain 5-HT system is a major target for several psychiatric disorders such as tricyclic antidepressants, selective serotonin reuptake inhibitors, monoamine oxidase inhibitors, and psychostimulants (Lucki, 1998; Gainetdinov and Caron, 2003).

Tryptophan hydroxylase (TPH) is the rate-limiting enzyme in 5-HT synthesis, which catalyzes the hydroxylation of L-tryptophan. Two isoforms (TPH1 and TPH2) having tryptophan hydroxylating activity were identified (Kuhn et al., 1980;

\footnotetext{
Received May 7, 2005; revised Aug. 16, 2005; accepted Nov. 21, 2005.

This work was supported in part by research grants from the Ministry of Education, Science, Technology, Sports and Culture of Japan. We thank Dr. Whittemore (University of Louisville) and Dr. Stoll (Texas Tech School of Pharmacy) for the generous gifts of RN46A cells and TPH1 CDNA clone, respectively. We also thank Dr. Manabe (University of Tokyo), Dr. Aiba (Kobe University), and Dr. Bito (University of Tokyo) for critical reading.

Correspondence should be addressed to Kazuhiro Nakamura, Department of Pathology, Juntendo University

School of Medicine, 2-1-1, Hongo, Bunkyo-ku, Tokyo 113-8421, Japan. E-mail: kaz@med.juntendo.ac.jp.

Y. Xiu's present address: Department of Immunology, Duke University Medical Center, Durham, NC 27710.

DOI:10.1523/JNEUROSCI.1835-05.2006

Copyright $\odot 2006$ Society for Neuroscience $\quad 0270-6474 / 06 / 260530-05 \$ 15.00 / 0$
}

Hasegawa and Ichiyama, 1987; Walther et al., 2003; Zhang et al., 2004). TPH 2 mRNA was reported to be preferentially expressed in the brain (Walther et al., 2003). In contrast, TPH1 mRNA was reported to be barely detected in the brain and instead to be mainly expressed in the pineal gland and the periphery (Walther et al., 2003). Thus, the role of TPH1 in serotonin synthesis in the brain is not explored.

Nevertheless, TPH1 gene has been the subject of intensive study regarding its possible involvement in many psychiatric and behavioral traits. Polymorphisms within the TPH1 gene have been reported to be associated with suicidal behavior (Mann et al., 1997; Nielsen et al., 1998; Rujescu et al., 2003; Bellivier et al., 2004). Furthermore, the polymorphisms are closely implicated in antidepressant response in patients with unipolar major depression (Peters et al., 2004).

Considering subtle TPH1 expression in the brain (Walther et al., 2003), it seems to be difficult to elucidate the functional link between TPH1 polymorphisms and psychiatric disorders. However, based on the observation in rats that the TPH1 $m R N A$ level peaked at postnatal day 22 (P22) and then declined between P22 and P61 in the dorsal raphe nucleus, which correlated well with tryptophan hydroxylase enzyme activities in raphe (Rind et al., 2000), TPH1 may affect 5-HT levels specifically in the developing brain. In addition to its action as a crucial neurotransmitter in various regions in the adult brain, 5-HT is essential for development of 5-HT neurons in an autocrine manner (Gaspar et al., 
2003). Thus, changes in brain 5-HT contents during development could disturb development of 5-HT neurons, which might cause permanent changes in adult behavior.

In the present investigation, we sought to ask the hypothesis by estimating kinetic properties of TPH1 in a condition mimicking that of the developing brain. 5-HT contents in vivo were also studied using brains from several mouse strains. Finally, we assessed depression-related behavior of mice showing low TPH1 expression during development.

\section{Materials and Methods}

Animals. SWR/J mice were obtained from The Jackson Laboratory (Bar Harbor, ME). Other mice were obtained from Shizuoka Laboratory Animal Center (Shizuoka, Japan). Animals were maintained according to the guidelines of Juntendo University.

Reverse transcription-PCR and in situ hybridization. Reverse transcription-PCR was done using total RNA derived from brain and primers: TPH1, 5'-GCTCTCAAAATACTGTGGCTATCGG-3' and 5'AACCTGAACACTCTGTGTGTACGG-3'; TPH2, 5'-CACTGCTCTTCAGCACCAGGGTTCTGGACA- ${ }^{\prime}$ and $5^{\prime}$-GGAACCACGGCACATCCTCGAGATCTTCTT-3'; glyceraldehyde-3-phosphate dehydrogenase $(G A P D H), \quad 5^{\prime}$-CGACTGCCCAGAACATCATCCCTGC-3' and 5'TTAGTGGGCCCCTGGATGCCAGCTT-3'. Because 27 PCR cycles yielded products that were in the linear range of logarithm, we chose 27 and 40 cycles. GAPDH was used for internal control. Relative product densities for multiple experiments were estimated. For in situ hybridization, sense and antisense digoxigenin-labeled cRNA probes specific to TPH1 were designed according to the study by Côté et al. (2003). In situ hybridization was done using coronal brain sections from C57BL/6 mice, $250 \mu \mathrm{m}$ in thickness, essentially as described previously (Ravassard et al., 1997). Signals were visualized with anti-digoxigenin-conjugated alkaline phosphatase and bromo-4-chloro-3-indolyl phosphate/nitroblue tetrazolium substrate (Vector Laboratories, Burlingame, CA). The sense control probe gave no signals (data not shown).

Sequencing and luciferase reporter assay. The 5'-flanking sequences $(-430$ to +117 relative to the transcription start site) and a $209 \mathrm{bp}$ fragment from the $3^{\prime}$-untranslated regions (UTRs) of the TPH1 gene were generated by PCR from genomic DNA of C57BL/6, C57BL/10, $\mathrm{C} 3 \mathrm{H}$, New Zealand black (NZB), New Zealand white (NZW), and SWR mice, using appropriate primers. Sequencing analysis was performed using the fragments.

To yield luciferase constructs, the PCR product of the promoter region from NZB or NZW mice was inserted into upstream of the luciferase coding region of the pGL3-Basic vector (Promega, Madison, WI), and those of the 3'UTRs were inserted into downstream of the luciferase coding region of the pGL3-Promoter vector having the cytomegalovirus promoter (Promega). Differentiated RN46A cells $\left(1 \times 10^{6}\right)$ were transiently transfected with $5 \mu \mathrm{g}$ of each luciferase construct by electroporation using a Gene pulser (300 V/950 $\mu$ F; Bio-Rad, Hercules, CA). Two days after electroporation, luciferase activity was measured for a $20 \mathrm{~s}$ time course with the use of a dual system (Promega) and a luminometer (Lumat LB 9507; Berthold, Wildbad, Germany). The relative luciferase activities were expressed based on the activity of the construct without the promoter (pGL3-Basic vector) or that without the 3'UTR of TPH1 (pGL3-Promoter vector).

Neurochemical analysis. To examine TPH1 and TPH2 enzyme activities, the coding region of the TPH1 or TPH2 gene was inserted into the NotI-ApaI fragment of pMT/V5-HisB (Invitrogen, Carlsband, CA) to yield pMTTPH1His or pMTTPH2His. The NotI-PmeI fragment from pMTTPH1His or pMTTPH2His, including the coding region of each gene, and the histidine hexamer region was blunted and ligated with NotI-digested and blunted pUC-CAGGS (Niwa et al., 1991). Then, $5 \times$ $10^{6} \mathrm{Cos} 7$ cells grown to subconfluence were transiently transfected with $20 \mu \mathrm{g}$ of each expression plasmid (pCAGTPH1His or pCAGTPH2His) by electroporation $(300 \mathrm{~V} / 950 \mu \mathrm{F})$. Two days after transfection, cells were harvested, and the amount of TPH1 or TPH2 protein fused to the histidine hexamer was evaluated by Western blot analysis using anti- histidine-hexamer antibody (Sigma, St. Louis, MO). Then, the TPH activity was determined through a three-step procedure (Iida et al., 2002).

For the quantitation of tissue tryptophan, the brainstem of male mice at P21 was dissected under anesthesia with diethyl ether and frozen at $-80^{\circ} \mathrm{C}$ until analysis. Tissues were homogenized in $0.1 \mathrm{~N} \mathrm{HCl}$ then deproteinized in $1 \mathrm{~m}$ perchloric acid. Determinations were made using an HPLC system equipped with a fluorescence monitor (model FP920; JASCO, Tokyo, Japan) set at 290 and $350 \mathrm{~nm}$ for excitation and emission, respectively. The solid phase was octadecyl silica $(4.6 \times 250 \mathrm{~mm}$; Jasco Finepak SIL-C18T5), the mobile phase was a 100:5:10 mixture of $40 \mathrm{~mm}$ sodium acetate (adjusted to $\mathrm{pH} 3.5$ with formic acid), acetonitrile, and methanol, and the flow rate was $1 \mathrm{ml} / \mathrm{min}$.

The determination of tissue tetrahydrobiopterin was determined by a differential oxidation procedure as described previously (Sawabe et al., 2004).

Immunohistochemistry. Animals were deeply anesthetized by injection of pentobarbital- $\mathrm{Na}(5 \mathrm{mg} / \mathrm{animal}$, i.p.) and then perfused transcardially with saline followed by a fixative solution [4\% PFA in $0.1 \mathrm{M}$ phosphate buffer $(\mathrm{PB})]$. The brains were dissected out from the skull and postfixed overnight at $4^{\circ} \mathrm{C}$ in the same fixative solution. Then, brains were immersed in $0.1 \mathrm{M} \mathrm{PB}$ containing $30 \%$ sucrose until they sank. For the immunohistochemistry of 5-HT, the sections ( $50 \mu \mathrm{m}$ in thickness) were incubated with anti-5-HT antibody (Chemicon, Temecula, CA) and visualized with $0.05 \% 3,3^{\prime}$-diaminobenzidine tetrahydrochloride and $0.01 \% \mathrm{H}_{2} \mathrm{O}_{2}$ in $50 \mathrm{~mm}$ Tris- $\mathrm{HCl}, \mathrm{pH}$ 7.5. The intensities of signals were quantitatively estimated using NIH Image.

Behavioral tests. For the forced swim test, a cylindrical container (height, $50 \mathrm{~cm} ; 20 \mathrm{~cm}$ in diameter) with $30 \mathrm{~cm}$ of water maintained at $22^{\circ} \mathrm{C}$ was used. Behavior in the water was categorized into immobility or swimming, and immobility time was counted. Immobility time was assessed using two different schedules. The test was done during $15 \mathrm{~min}$ on the first day. After $24 \mathrm{~h}$, mice were placed in the water for $5 \mathrm{~min}$ again. In addition, to assess the effects of antidepressants, the test was done during $5 \mathrm{~min}$. Paroxetine ( $8 \mathrm{mg} / \mathrm{kg}$, s.c.; GlaxoSmithKline, Uxbridge, UK) or imipramine (30 mg/kg, i.p.; Sigma) was injected $30 \mathrm{~min}$ before the test. Paroxetine and imipramine were dissolved in water and saline, respectively.

For the tail suspension test, mice were fastened with adhesive tape by the tip $(2 \mathrm{~cm})$ of the tail to a flat steel bar placed horizontally at the height of $30 \mathrm{~cm}$ above the ground in a white Plexiglas box that isolated the mouse from visual distractions while permitting observation of behavior. The presence or absence of immobility, defined as the absence of limb movement, was examined during a 5 min test session.

Statistics. Statistical significance was set at $p<0.05$ using Student's $t$ test.

\section{Results}

To explore the possible role of TPH1 in the brain, we first assessed TPH1 mRNA expression levels in the C57BL/6 mouse brainstem at P7, P21, and 2 months by semiquantitative RT-PCR using specific primers. The TPH1 expression was highest at P21 (Fig. $1 A)$. The expression was not detected at P7. Similarly, TPH1 mRNA expression was detected in the raphe nucleus of C57BL/6 mice at P2 1 by in situ hybridization using a digoxygenin-labeled TPH1-specific riboprobe (Fig. $1 B$ ). However, only faint signal was detected in adulthood. In contrast, apparent difference was not found in TPH 2 mRNA levels between P21 and adult stage (Fig. 1A). Our observation was in line with a previous report in rats that the TPH1 $m$ RNA level peaked at P22 and then declined between P22 and P61 in the dorsal raphe nucleus of rats (Rind et al., 2000).

Sophisticated analysis using human TPH1 or TPH2 fusion protein elucidated different kinetic properties between the two enzymes (McKinney et al., 2005), in which fusion proteins from Escherichia coli and in vitro transcription/translation system were assessed in various tryptophan and 6R-L-erythro-5,6,7,8tetrahydrobiopterin $(\mathrm{BH} 4)$ concentrations. However, the kinetic 
properties were not determined at tryptophan and BH4 concentrations reflecting those in the brain. We extended the analysis in a condition mimicking the brainstem of a P21 mouse. Histidine hexamer-tagged mouse TPH1 or TPH2 protein was expressed in Cos7 cells, and the dependence of the enzyme activities of TPH1 and TPH2 on concentrations of the substrate tryptophan and the cosubstrate $\mathrm{BH} 4$ were compared with the respective cell extracts (Fig. 1C). The expression level of TPH1 or TPH2 fusion protein was estimated by Western blot analysis using anti-histidine hexamer antibody. The efficiency of the 5-HT precursor, 5-hydroxytryptophan (5HTP), formation of TPH1 was much higher than that of TPH2 at all concentrations of BH4 and tryptophan. Apparent $K_{\mathrm{m}}$ values for tryptophan at $400 \mu \mathrm{M} \mathrm{BH} 4$ were 16.6 and $19.2 \mu \mathrm{M}$ in TPH1 and TPH2, respectively. However, the affinity was much higher in TPH1 at a lower concentration of BH4; the $K_{\mathrm{m}}$ was $7.5 \mu \mathrm{M}$ for tryptophan at $4 \mu \mathrm{M} \mathrm{BH} 4$, whereas that of TPH2 was constant $(19.2 \mu \mathrm{M})$, suggesting that TPH1 sustains enzyme activity even with lowered tryptophan levels under possible BH4-limiting conditions.

We determined tissue $\mathrm{BH} 4$ and tryptophan contents in the brainstem of various mouse strains at $\mathrm{P} 21$. $\mathrm{BH} 4$ content was $\sim 0.9 \mathrm{nmol} / \mathrm{g}$. Assuming an even distribution of $\mathrm{BH} 4$ in the tissue, $\sim 1 \mu \mathrm{M}$ could be estimated, which was far less than the $K_{\mathrm{m}}$ values of both TPH1 and TPH2 for BH4 $(\sim 20 \mu \mathrm{M})$. Because tryptophan content was between 15 and $30 \mathrm{nmol} / \mathrm{g}$ wet tissue, the $K_{\mathrm{m}}$ of TPH2 for tryptophan $(19.2 \mu \mathrm{M})$ was around the tissue tryptophan level, whereas the $K_{\mathrm{m}}$ of TPH1 for tryptophan $(7.5 \mu \mathrm{M})$ was several-fold lower than the tissue level at the $\mathrm{BH} 4$ concentration (4 $\mu \mathrm{M})$, essentially reflecting that in the brainstem of P21 mouse. Under the conditions mimicking the brainstem of a P21 mouse, higher affinity to tryptophan of TPH1 was apparent, and higher efficiency of 5-HTP formation of TPH1 was also observed in our condition.

Then, we determined the contribution of TPH1 to brain 5-HT contents in vivo. Because constitutive genetic deletions of serotonergic molecules can lead to compensatory changes (Ramboz et al., 1998; Dulawa et al., 2000), we used several strains of laboratory mice. Promoter and 3'UTRs of genes affect the expression level. We isolated the two regions of TPH1 gene from C57BL/6, C57BL/10, $\mathrm{C} 3 \mathrm{H}, \mathrm{NZB}, \mathrm{NZW}$, and SWR mice and performed sequencing analysis. We found polymorphisms in the promoter region (Fig. $2 A$, top). Notably, NZW and SWR mice had common polymorphisms, including putative Sp1 binding site. To ask whether the polymorphisms shared by NZW and SWR mice affect TPH1 ex-
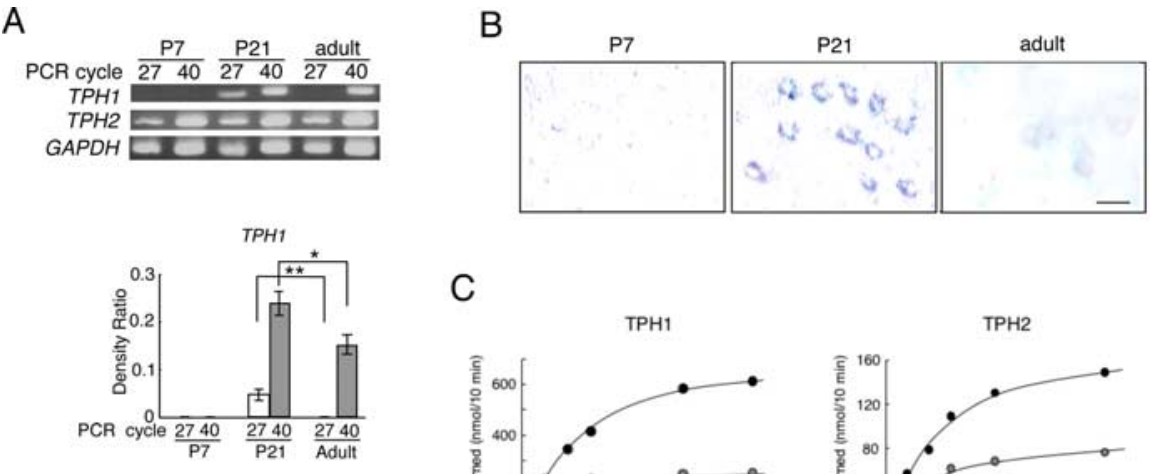

C
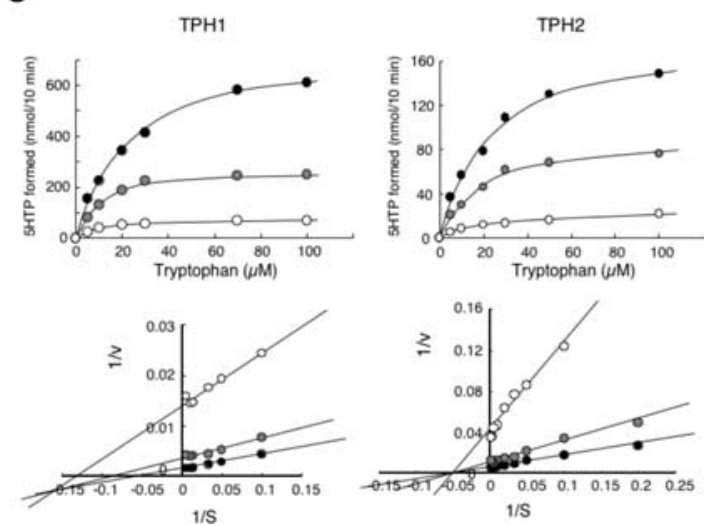

Figure 1. Characterization of TPH1 and TPH2. $\boldsymbol{A}, \boldsymbol{B}$, Developmental change in the expression of TPH1 and TPH2 $\mathrm{mRNAs}$ in the brainstem. Brains of C57BL/6 mice at P7, P21, and adult stage were studied using semiquantitative RT-PCR with 27 or 40 cycles (TPH1 and TPH2) (A) or in situ hybridization (TPH1) (B). Plots of ratio of TPH1 and TPH2 product densities to those of GAPDH are also shown $\left(n=4\right.$, each) $(\boldsymbol{A})$. Scale bar, $20 \mu \mathrm{m}$. Error bars represent mean \pm SEM. ${ }^{*} p<0.05$; ${ }^{* *} p<0.01$. C, Comparison of the kinetics between TPH1 and TPH2. The top panels are the Michaelis-Menten plots of tryptophan hydroxylase activity (TPH1/left vs $\mathrm{TPH} 2 /$ right) versus tryptophan concentrations at three different concentrations of BH4 (4 $\mu \mathrm{m}$, open circle; $40 \mu \mathrm{m}$, gray circle; $400 \mu \mathrm{m}$, closed circle). The bottom panels are corresponding double reciprocal plots. $K_{\mathrm{m}}$ values estimated at the extrapolated cross points for TPH1 were $16.6,11.4$, and $7.5 \mu \mathrm{m}$ at 400, 40, and $4 \mu \mathrm{MBH} 4$, respectively, and $19.2 \mu \mathrm{m}$ at all BH4 concentrations for TPH2.
A

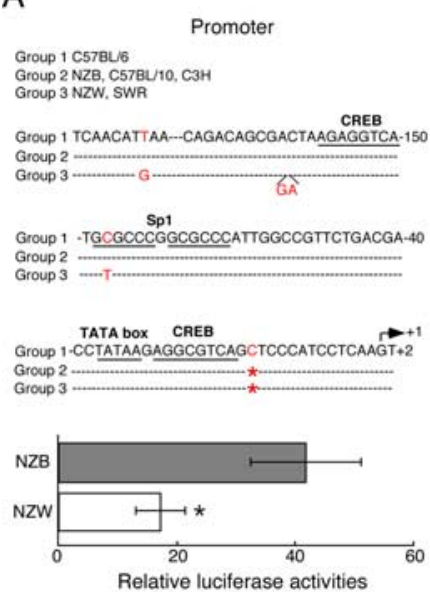

B
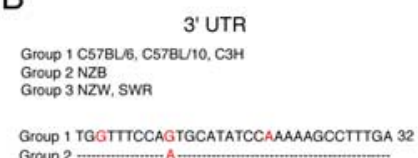
Group 1 TGGITCCAGTGCATATCCAAAAAGCCTITGA

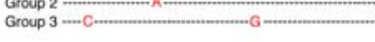
Group 1 -CTAG-..-AATGT-.-CATATTCA-GGAACCTGC 211

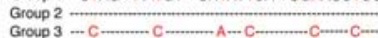

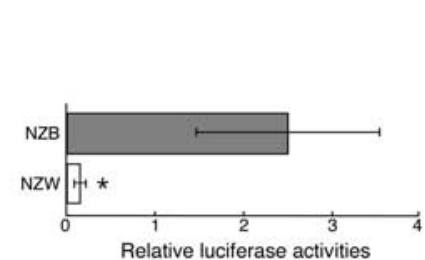

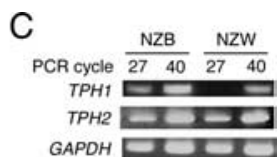

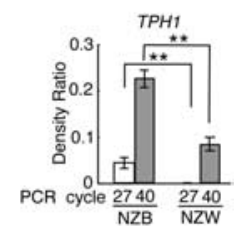

TPH2

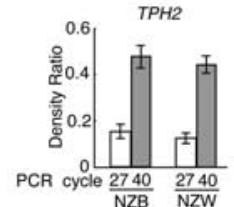

Figure 2. Functional polymorphisms in the TPH1 gene in NZW and SWR mice. $\boldsymbol{A}, \boldsymbol{B}$, Sequences of the promoter $(\boldsymbol{A})$ and $3^{\prime}$ UTR (B) of TPH1 from several strains (top) and luciferase activities using sequences from NZB and NZW mice (bottom). The sequence is numbered relative to the transcription initiation site $(+1)(\boldsymbol{A})$ or the $3^{\prime}$ UTR initiation site $(\boldsymbol{B})$. Identity and a single base pair deletion are indicated by - and ${ }^{*}$, respectively. Mismatch is indicated by the corresponding nucleotides. Putative transcription factor binding sites are underlined according to the study by Stoll and Goldman (1991). C, Comparison of TPH1 and TPH2 mRNA levels between NZB and NZW mouse brains at P21 using semiquantitative RT-PCR with 27 or 40 cycles. Plots of ratio of TPH1 and $\mathrm{TPH} 2$ product densities to those of GAPDH are also shown $\left(n=4\right.$, each). Error bars represent mean \pm SEM. ${ }^{* *} p<0.01$.

pression level, we did luciferase reporter assay. The TPH1 gene fragment of the promoter region from NZB or NZW mice was linked to the luciferase coding region, and each construct was transfected into RN46A cells, a serotonergic cell line established from embryonic raphe (White et al., 1994). The relative luciferase activity of the promoter region from NZW mice was significantly lower than that of the NZB mice (Fig. $2 \mathrm{~A}$, bottom).

We also found common polymorphisms in the $3^{\prime}$ UTR of 


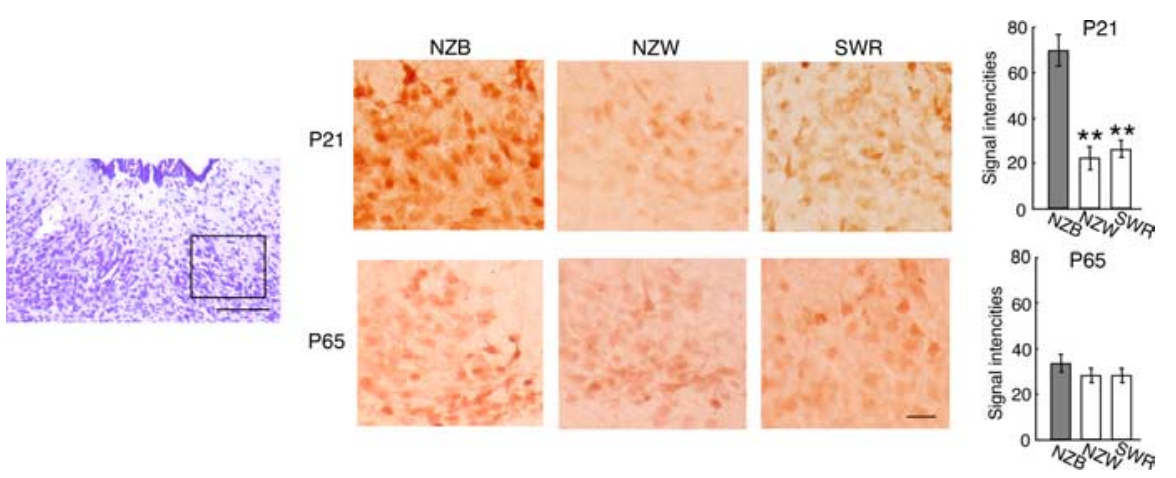

Figure 3. Decreased 5-HT levels in the developing raphe nucleus of NZW and SWR mice. Lateral parts of dorsal raphe nucleus, indicated by the open square in the Niss--stained coronal sections of the brainstem (left), were stained with anti-5-HT antibody in NZB, NZW, and SWR mice at P21 and P65. The intensities of signals were quantitatively shown (right). Scale bars: left, $200 \mu \mathrm{m}$; middle, $50 \mu \mathrm{m}$. Error bars represent mean \pm SEM. ${ }^{* *} p<0.01$.
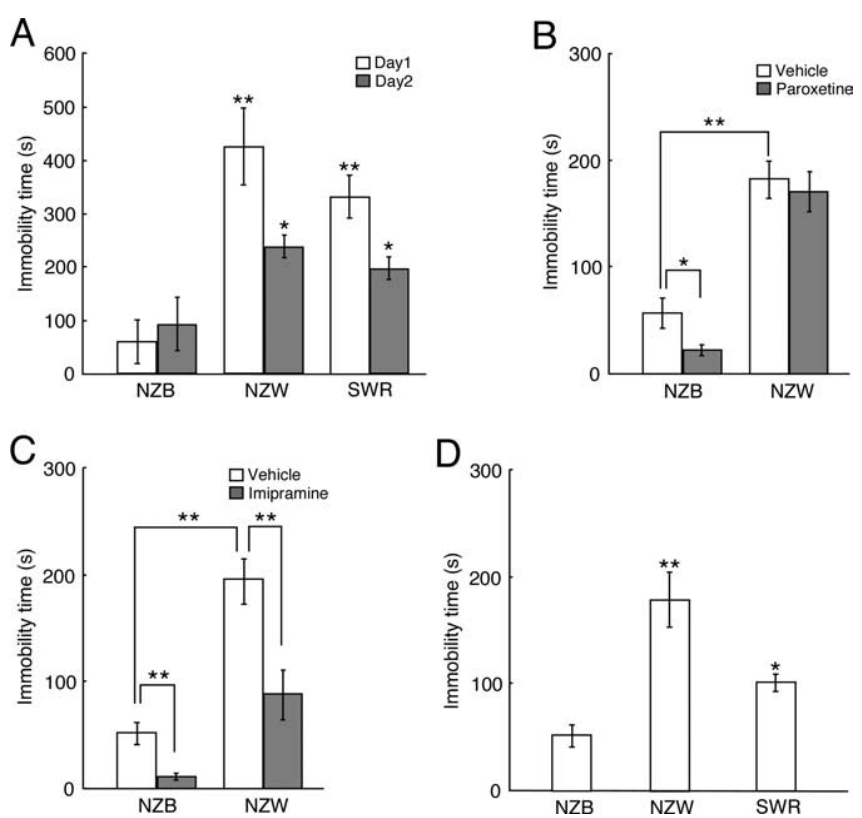

Figure 4. Depression-related behavior. $\boldsymbol{A}-\boldsymbol{C}$, Forced swim test. Immobility time was measured during 15 min on day 1 and 5 min on day 2 in NZB $(n=6), \operatorname{NZW~}(n=12)$, and SWR ( $n=$ 8) mice $(\boldsymbol{A})$. To assess the effects of antidepressants, immobility time of paroxetine-treated NZB $(n=6)$ or NZW $(n=7)$ mice was compared with that of vehicle-treated mice $(n=7$, each) during $5 \mathrm{~min}(\boldsymbol{B})$. Imipramine-treated NZB $(n=7)$ or NZW $(n=7)$ mice were also compared with vehicle-treated mice during $5 \min (n=7$ and 8 , respectively) (C). D, Tail suspension test. Immobility time was measured during $5 \min$ in NZB $(n=7)$, NZW $(n=7)$, and SWR $(n=8)$ mice. Error bars represent mean \pm SEM. ${ }^{*} p<0.05,{ }^{* *} p<0.01$.

NZW and SWR mice (Fig. 2B, top). 3'UTR regulates mRNA stability and translation. The luciferase activity of the construct having the TPH1 3'UTR from NZW mice was weaker than that of NZB mice (Fig. $2 B$, bottom). Thus, the polymorphisms in both the promoter and 3' UTR of the TPH1 gene proved to affect TPH1 expression. Consistently, TPH1 mRNA expression level in the brainstem of NZW mice at P21 was lower than that of NZB mice (Fig. 2C).

Remarkably, immunohistochemistry revealed that 5-HT levels in the dorsal raphe nucleus were lower in NZW and SWR mice than NZB mice at P21 (Fig. 3), which was also the case in the median raphe nucleus (data not shown). However, essentially no difference was found in adulthood.

TPH2 mRNA levels were comparable between NZB and NZW mice at P21 (Fig. 2C), and no polymorphisms were found in the coding region of the TPH2 gene from NZW and SWR mice (data not shown). In addition, we did not detect the differences in the expression of monoamine oxidase A and serotonin transporter between NZB and NZW mice (data not shown). Thus, the lower 5-HT levels in the raphe nucleus of NZW mice at 3 weeks of age seems to be attributable to low TPH1 expression.

We then sought to determine the effect of the low TPH1 expression in the developing brain on adult behavior using adult NZW and SWR mice. Because the polymorphisms in the TPH1 gene showed significant association when response to fluoxetine is compared with nonresponse in patients with unipolar major depression (Peters et al., 2004), we initially chose the forced swim test, a behavioral test for the animal model of depression (Porsolt et al., 1977). On the first day, the mouse was placed in the water for $15 \mathrm{~min}$. The mouse showed swimming or immobility. The immobility time was counted as an index of depression-related behavior. On the next day, the mouse was again introduced in the water and was tested for $5 \mathrm{~min}$. As shown in Figure $4 A$, longer immobility times were observed in NZW and SWR mice than in NZB mice on both days 1 and 2 .

We then examined whether antidepressants could overcome the longer immobility time in NZW mice. NZB or NZW mice treated with vehicle or selective serotonin reuptake inhibitor paroxetine were subjected to the forced swim test for $5 \mathrm{~min}$ (Fig. $4 \mathrm{~B}$ ). Again, the vehicle-treated NZW mice showed longer immobility time than the vehicle-treated NZB mice. Paroxetine treatment decreased immobility in NZB mice but not in NZW mice, suggesting that low 5-HT levels during development in NZW mice might induce functional alterations in 5-HT system. In contrast, imipramine treatment partially decreased immobility in NZW mice (Fig. 4C). Likewise, NZW and SWR mice showed longer immobility time than NZB mice in the tail suspension test (Fig. $4 D$ ), another animal model of depression (Steru et al., 1985). Because motor performance in the runway task was indistinguishable between NZB and NZW mice (K. Nakamura, S. Hirose, unpublished data), the longer immobility time in the two tests seems not to be caused by impaired general motor ability. Thus, adult NZW and SWR mice showed depression-like behavior in the two tests.

\section{Discussion}

We explored the developmental stage-specific role of TPH1. Of particular importance is that our inspection of kinetic comparison between TPH1 and TPH 2 was assessed in a condition reflecting that of the developing brainstem, that is, low BH4 concentration $(4 \mu \mathrm{M})$. In such a condition, higher affinity to tryptophan of TPH1 and higher enzyme activity of TPH1 than of TPH2 were apparent. The $K_{\mathrm{m}}$ of TPH2 for tryptophan was around the tissue tryptophan level, whereas the $K_{\mathrm{m}}$ of TPH1 for tryptophan was several-fold lower than the tissue level. These data likely suggest that TPH1 uses tryptophan to synthesize 5-HT more efficiently than TPH2, and TPH1 exerts most of its full activity with respect to tryptophan dependence. Because TPH1 was expressed predominantly during the late developmental stage, 5-HT contents during the period might be affected by TPH1 expression level. Indeed, NZW and SWR mice having low TPH1 expression 
showed low brain 5-HT contents only during development in vivo. Thus, TPH1 is involved in 5-HT levels in the brain during late developmental stage but not in the adult.

5 -HT acts as a crucial neurotransmitter in various regions in the adult brain and is closely implicated in psychiatric disorders (Lesch et al., 1996; Lucki, 1998; Shih et al., 1999; Gainetdinov and Caron, 2003; Lesch, 2004). Because 5-HT synthesis in the adult brain is dependent on TPH2 (Walther et al., 2003), polymorphisms in TPH2 might affect 5-HT levels in the adult. Numerous genetic association analyses will be needed to determine whether $\mathrm{TPH} 2$ is involved in psychiatric conditions.

The human TPH1 gene represents candidate genes for psychiatric conditions. The TPH1 intron 7 A779C polymorphism has been reported to be associated with suicidal behavior in depressed patients (Mann et al., 1997) and in alcoholic offenders (Nielsen et al., 1998). Meta-analyses also provided evidence for an association of suicide-related behavior with TPH1 polymorphism (Rujescu et al., 2003; Bellivier et al., 2004). TPH1 may contribute to psychiatric conditions without affecting brain 5-HT levels in the adult. 5-HT has an additional role during development. 5-HT is essential for the development of 5-HT neurons such as neurogenesis, apoptosis, axon branching, dendritogenesis, and the fine wiring of brain connections in an autocrine manner (Gaspar et al., 2003). Targeted deletions of molecules involved in 5-HT metabolism or transport in mice affected dendritic maturation during development (Gaspar et al., 2003). However, gross abnormalities were not found in these mice. TPH1 expression could not be detected using RT-PCR at P7. Instead, TPH1 was expressed at later developmental stage. Thus, TPH1 is likely involved in the fine-tuning or maturation of 5-HT neurons, which might cause permanent changes in adult behavior. We showed depression-related behavior in adult NZW and SWR mice using the forced swim test and tail suspension test. Both mice are suitable strains to study the roles of TPH1 during childhood in behavior in the adult. Altered response to paroxetine treatment in NZW mice may be caused by functional changes in 5-HT neuronal circuit or 5-HT receptors. Considering neurodevelopmental models of psychiatric disorders (Luna and Sweeney, 2001), the relationship between the polymorphisms in the TPH1 gene and functional neurodevelopmental abnormalities might be considered in patients with psychiatric disorders. Our study opens a new avenue for understanding of temporally distinct contribution of each TPH to 5-HT neuronal functions associated with psychiatric disorders.

\section{References}

Bellivier F, Chaste P, Malafosse A (2004) Association between the TPH gene A218C polymorphism and suicidal behavior: a meta-analysis. Am J Med Genet B Neuropsychiatr Genet 124:87-91.

Côté F, Thevenot E, Fligny C, Fromes Y, Darmon M, Ripoche MA, Bayard E, Hanoun N, Saurini F, Lechat P, Dandolo L, Hamon M, Mallet J, Vodjdani G (2003) Disruption of the nonneuronal tph1 gene demonstrates the importance of peripheral serotonin in cardiac function. Proc Natl Acad Sci USA 100:13525-13530.

Dulawa SC, Gross C, Stark KL, Hen R, Geyer MA (2000) Knockout mice reveal opposite roles for serotonin $1 \mathrm{~A}$ and $1 \mathrm{~B}$ receptors in prepulse inhibition. Neuropsychopharmacology 22:650-659.

Gainetdinov RR, Caron MG (2003) Monoamine transporters: from genes to behavior. Annu Rev Pharmacol Toxicol 43:261-284.

Gaspar P, Cases O, Maroteaux L (2003) The developmental role of serotonin: news from mouse molecular genetics. Nat Rev Neurosci 4:1002-1012.

Hasegawa H, Ichiyama A (1987) Tryptophan 5-monooxygenase from mouse mastocytoma: high-performance liquid chromatography. Methods Enymol 142:88-92.

Iida Y, Sawabe K, Kojima M, Oguro K, Nakanishi N, Hasegawa H (2002)
Proteasome-driven turnover of tryptophan hydroxylase is triggered by phosphorylation in RBL2H3 cells, a serotonin producing mast cell line. Eur J Biochem 269:4780-4788.

Kuhn DM, Meyer MA, Lovenberg W (1980) Comparisons of tryptophan hydroxylase from a malignant murine mast cell tumor and rat mesencephalic tegmentum. Arch Biochem Biophys 199:355-361.

Lesch KP (2004) Gene-environment interaction and the genetics of depression. J Psychiatry Neurosci 29:174-184.

Lesch KP, Bengel D, Heils A, Sabol SZ, Greenberg BD, Petri S, Benjamin J, Muller CR, Hamer DH, Murphy DL (1996) Association of anxietyrelated traits with a polymorphism in the serotonin transporter gene regulatory region. Science 274:1527-1531.

Lucki I (1998) The spectrum of behaviors influenced by serotonin. Biol Psychiatry 44:151-162.

Luna B, Sweeney JA (2001) Studies of brain and cognitive maturation through childhood and adolescence: a strategy for testing neurodevelopmental hypotheses. Schizophr Bull 27:443-455.

Mann JJ, Malone KM, Nielsen DA, Goldman D, Erdos J, Gelernter J (1997) Possible association of a polymorphism of the tryptophan hydroxylase gene with suicidal behavior in depressed patients. Am J Psychiatry 154:1451-1453.

McKinney J, Knappskog PM, Haavik J (2005) Different properties of the central and peripheral forms of human tryptophan hydroxylase. J Neurochem 92:311-320.

Nielsen DA, Virkkunen M, Lappalainen J, Eggert M, Brown GL, Long JC, Goldman D, Linnoila M (1998) A tryptophan hydroxylase gene marker for suicidality and alcoholism. Arch Gen Psychiatry 55:593-602.

Niwa H, Yamamura K, Miyazaki J (1991) Efficient selection for highexpression transfectants with a novel eukaryotic vector. Gene 108:193-199.

Peters EJ, Slager SL, McGrath PJ, Knowles JA, Hamilton SP (2004) Investigation of serotonin-related genes in antidepressant response. Mol Psychiatry 9:879-889.

Porsolt RD, Le Pichon M, Jalfre M (1977) Depression: a new animal model sensitive to antidepressant treatments. Nature 266:730-732.

Ramboz S, Oosting R, Amara A, Kung HF, Blier P, Mendelsohn M, Mann JJ, Brunner D, Hen R (1998) Serotonin receptor 1A knockout: an animal model of anxiety-related disorder. Proc Natl Acad Sci USA 95:14476-14481.

Ravassard P, Chatail F, Mallet J, Icard-Liepkalns C (1997) Relax, a novel rat bHLH transcriptional regulator transiently expressed in the ventricular proliferating zone of the developing central nervous system. J Neurosci Res 48:146-158.

Rind HB, Russo AF, Whittemore SR (2000) Developmental regulation of tryptophan hydroxylase messenger RNA expression and enzyme activity in the raphe and its target fields. Neuroscience 101:665-677.

Rujescu D, Giegling I, Sato T, Hartmann AM, Moller HJ (2003) Genetic variations in tryptophan hydroxylase in suicidal behavior: analysis and meta-analysis. Biol Psychiatry 54:465-473.

Sawabe K, Wakasugi KO, Hasegawa H (2004) Tetrahydrobiopterin uptake in supplemental administration: elevation of tissue tetrahydrobiopterin in mice following uptake of the exogenously oxidized product 7,8 dihydrobiopterin and subsequent reduction by an anti-folate-sensitive process. J Pharmacol Sci 96:124-133.

Shih JC, Chen K, Ridd MJ (1999) Monoamine oxidase: from genes to behavior. Annu Rev Neurosci 22:197-217.

Steru L, Chermat R, Thierry B, Simon P (1985) The tail suspension test: a new method for screening antidepressants in mice. Psychopharmacology (Berl) 85:367-370.

Stoll J, Goldman D (1991) Isolation and structural characterization of the murine tryptophan hydroxylase gene. J Neurosci Res 28:457-465.

Walther DJ, Peter JU, Bashammakh S, Hortnagl H, Voits M, Fink H, Bader M (2003) Synthesis of serotonin by a second tryptophan hydroxylase isoform. Science 299:76.

White LA, Eaton MJ, Castro MC, Klose KJ, Globus MY, Shaw G, Whittemore SR (1994) Distinct regulatory pathways control neurofilament expression and neurotransmitter synthesis in immortalized serotonergic neurons. J Neurosci 14:6744-6753.

Zhang X, Beaulieu JM, Sotnikova TD, Gainetdinov RR, Caron MG (2004) Tryptophan hydroxylase- 2 controls brain serotonin synthesis. Science 305:217. 